\title{
APPENDIX: STANDARDIZED FORMS
}

\section{SOCIAL SERVICE JOB DESCRIPTION SAMPLE}

Social Service Department

Job: Director of Social Services

Reporting to: Facility Administrator

Statement of Purpose:

The social worker in is to provide social services to residents in the nursing facility through the identification of the resident's psychosocial, mental, and emotional needs and provide or aid in the access of services to meet these needs. The focus is to provide the highest practical level of physical, mental, and psychosocial well-being, and quality of life attainable by the facility residents.

Qualifications:

The incumbent must be a social worker who holds the minimum of a -bachelor's degree in Social Work, Psychology, Human Services, or other related field and who is preferably licensed in the State of The social worker should have a minimum of 2 to 3 years of experience working with elders, preferably in long-term care, and competent social work skills.

Additional Qualifications:

Incumbents must have skills in communication, assessment, and social work methods and techniques. Incumbents should have the skills to provide support groups to resident, families, or staff as needed.

Primary Duties:

The social work department is responsible for a psychosocial assessment evaluation and development plan of care for all newly admitted residents that may include but is not limited to: 
Addressing resident's emotional and social factors relating to medical condition or treatment;

Resident's personal or interpersonal problems, issues, or needs while in the nursing facility;

Identifying present or future adjustment difficulties;

Addressing the probable length of stay;

Implementing varied approaches with staff to meet resident's needs;

Casework and group work as identified to resolve any social or emotional problems;

Community referrals as directed by resident need;

Assisting to obtain for the resident financial, legal, or community services as needed;

Acting as a liaison between the resident and the mental health agency/ provider;

Attending URC, Ethics Committee, Interdisciplinary, Administrative staff meetings and other meetings as requested;

Participating in, developing programs for Quality Assurance in the facility; Checking departmental documentation periodically to ensure all records are in compliance with Federal/State regulations;

Developing department policies and procedures of the Social Service Department and reviewing these annually making necessary changes and upgrades as needed;

Coordinating staff and family groups as needed.

Documentation:

The social work department provides timely entries in the resident's chart to include, but not limited to: a social service history of each resident as well as a psychosocial assessment. A care plan is formulated for each resident addressing problems, needs, and interventions. Documentation is provided to substantiate interventions, progress toward, and/or completion of goals. Documentation includes information pertaining to residents who are transferred from the facility.

Department Reporting:

The Social Service Department prepares and provides monthly reports of activities for the Facility Administrator. 
Discharge Planning:

Each resident will be assessed by the Social Service Department, as a member of the interdisciplinary team, for discharge. The Social Service Department will assist with plans for the resident's discharge and post-discharge with the resident, family, interdisciplinary team, and community resources. $\mathrm{He}$ or she will assist the resident and/or family in the implementation of the discharge plan and orientation around this process.

In-Service Training and Education:

In-service training is provided, on a continuing basis, for all the staff at the facility. This training, conducted by the social worker, deals with the orientation of the facility staff toward the creation of therapeutic community, congenial atmosphere, and healthy interpersonal relationships; enhances staff understanding of the normal aging process as well as issues around illness, need for dignity, quality of life, and placement. Training also instills the need, and the insight into, early recognition and treatment of psychosocial problems. Training and education will be offered to the community at large around issues of aging, rights of residents, facility services, and other related topics.

The social worker will continue to pursue education to increase own knowledge and skills.

Resident's Rights:

In-services are provided regularly by the Social Service Department for all staff on Resident's Rights and Abuse, Neglect, and Mistreatment, mandatory reporting law, as well as the facility policies regarding implementing these issues. The social worker acts as the resident's advocate. 


\section{INITIAL SOCIAL SERVICE HISTORY AND ASSESSMENT FORM}

There are multiple forms that have been designed to gather information about the history of a resident during the initial admission. These are adequate to obtain information about the resident; however, all forms limit spontaneous information and many forms do not necessarily reflect material that is requested for the MDS. The use of these forms can be

At initial admission as an informational gathering tool;

For a short-term admission in conjunction with the MDS information;

Replacement of an independent social service history.

Chart Location: These forms can be found in the Social Service section of the chart. The social service history should immediately follow the preadmission note(s) and precede any follow-up notes. 


\section{SOCIAL SERVICE HISTORY INITIAL ASSESSMENT}

Date of Admission:

Name:

Ethnicity:

Place of birth:

US citizen: Yes $\square$ No $\square$

Languages spoken:

Source of this information:

Diagnoses:

Reason for placement:

Expectations/Goals of this placement:

Brief physical description of the resident (include ambulatory status):

History of illness and/or accident/injury:

Previous hospitalizations:

Origin of family:

Parents' names:

If deceased, when and cause:

Siblings' names, addresses, phone numbers:

Closest siblings or friends to person:

Education:

Schools attended and last grade completed:

Military Service:

Occupation(s):

Where:

Type of work:

How long:

Date of retirement:

Names of spouse(s) (indicate whether still living):

Dates of marriage(s):

Description of relationship(s):
Source of Payment Upon Admission:

Sex: M $\square$ F $\square$ Marital Status: S M W D

Date of Birth:

Religion:

Date of immigration:

Is English understood?: Yes $\square$ No $\square$

Chart $\square$ Resident $\square$ Other: $\square$ 
If spouse is no longer living, indicate adjustment of resident to living alone: Children: Yes $\square$ No $\square$

Children's names, ages, addresses, and phone numbers:

Are any children deceased?

Describe personally; include psychosocial relationships with family, friends and whether these have changed:

Describe resident's use of spiritual comfort:

Describe mood, emotional status, and mental status, past and present; discuss whether resident has changed:

Ability to read: Yes $\square$ No $\square$

Write: Yes $\square$ No

Tell time: Yes $\square$ No $\square$

Has the resident ever been treated for depression, substance abuse, or a mental disorder? If so when, where, and with what response?

Is the resident presently receiving psychoactive medications? If yes, list below and note effectiveness. Note length of time, if known.

Describe the best approaches for working with the resident:

Resident strengths or skills:

Discharge plans:

Social service goals for this placement:

Information completed by:

Date: 


\section{QUARTERLY SOCIAL SERVICE NOTE FORM}

This form can be used to write quarterly progress notes or as reminder of areas to address within written progress notes. Interim notes should be written aside and provide backup to quarterly notes.

Use: 90-day review of resident progress toward goal(s).

Chart location: Quarterly notes are in the social service section of the chart. Generally, they are kept in chronological order, the last note at the back of the section. Quarterly notes of 2 to 3 years duration are generally kept. 


\section{SOCIAL SERVICE QUARTERLY PROGRESS NOTE}

Date of Review:

Resident Name: Room \#:

Date of Birth: Last Admission Date:

Hospitalizations during past quarter:

Mental Illness Diagnosis:

Yes $\square$ No $\square$

Developmental Disability Diagnosis:

Yes $\square$ No $\square$

Psych. Services:

Yes $\square$ No $\square$

Last Date of Service:

Counseling:

Yes $\square$ No $\square$

Medication Review:

Yes $\square$ No $\square$

Family Meetings During Last Quarter:

Yes $\square$ No $\square$

Room Changes:

Yes $\square$ No $\square$

Roommate Changes:

Yes $\square$ No $\square$

Pain Management:

Yes $\square$ No $\square$

Hospice:

Yes $\square$ No $\square$

Current Resident Status, Including Mental State, Physical Condition, Improvements or Deterioration:

Resident Discharge Potential:

Progress Toward Social Service Identified Goal(s):

New Goals: Yes $\square$ No $\square$

Social Service Signature and Title

EMB 2012 


\section{SOCIAL SERVICE EVALUATION FORM}

This is a sample form which can be utilized to evaluate the performance of a social worker within the Social Service Department. The focus is on social work skills within the role.

Use: This form can be utilized by the facility Administrator or the Director of Social Services as a part of the annual or biannual performance review of the facility social worker.

Place Located: The evaluation can be held in the personnel file of the social worker, as well as the worker having her own copy.

Caution: This should be a confidential evaluation, to be shared with only the Director of Social Services, the Administrator and the social worker who is being evaluated. 


\section{SOCIAL SERVICE EVALUATION}

\section{Facility:}

Name:

Date of Evaluation:

Position: Date of Hire:

Range of Evaluation: Excellent, Good, Fair, Poor

Ability to establish and maintain meaningful, effective, appropriately professional relationships with client system.

A. Attitudes as manifested in appropriate behavior toward client:

Interest and desire to be helpful

Empathic understanding

Nonjudgmental acceptance

Assent to client self-determination

Warmth and concern

Respect

B. Objective, disciplined use of self in

relationship on behalf of clients: Empathy and

sympathy without over-identification

C. Adherence to professionally accepted value in

client contact: Confidentiality

Social work process-knowledge and skills.

A. Information gathering skills:

Ability to gather relevant information from client

Observation and exploration of relevant

items are accurate and appropriately detailed

Discrimination ability to discern psychosocial

factors of significance that need to be explored

B. Assessment skills:

Effectively applied knowledge of human

behavior and social systems so as to derive

meanings from information gathering

Shows appreciation and understanding of client's 
perceptual cognitive and emotional frame of

reference

Capable of formulating a descriptive,

dynamic information assessment statement

C. Intervention skills:

To plan and implement a program of remediation based on assessment

Ability to use specific treatment

interventions, as appropriate to client's situation

Interventions are appropriately timed and relevant

D. Interviewing skills:

Ability to establish with client clear interview

purpose

Ability to maintain interview focus in order to

attain interview purpose

Maintains a good balance; flexibility;

responsibly following client lead and offering

appropriate directions and control

Ability to tactfully and nonthreateningly help client

communicate feelings as well as facts

E. Recording skills:

Timely

Coordinates with other team members

Content

\section{Facility.}

Knowledge of, commitment to, and

identification with facility objectives, policies,

and procedures

Ability to work within the limits of facility

policies and procedures 


\section{Supervision.}

A. Administrative aspects:

Prepares adequately for conference, provides

supervisor with necessary, appropriate material for conference

B. Interpersonal aspects:

Seeks and uses supervisor's help without undue dependency

Acceptance of supervision and instruction, positive orientation to supervisory authority

Ability to recognize when consultation is needed and how it might be appropriately used

\section{Staff and community relationships.}

Contributes to harmonious and effective relationships with facility staff at all levels Develops positive relationships with and makes appropriate use of colleagues from allied disciplines

Constructively represents the facility to other professionals and to the general public Has good knowledge of relevant community resources

\section{Management of work requirements and work load.}

Covers work load with regularity and adequacy

Shows ability to plan and organize work

schedule within time allotted

Shows capacity to set selective, valid priorities, and to schedule work accordingly Is prompt in submitting reports and recording 
Professionally related attributes and attitudes.

Realistic critical assessment of own limitations

without undue anxiety

Adequate level of self-awareness and capacity

for self-evaluation

Flexible and cooperative on the job

Behaves on the job in accordance with the values

and ethics of the profession

Provides creative solutions to problems

\section{Comments:}

Evaluation submitted by:

Reviewed with Social Worker: 


\section{INTERDISCIPLINARYTEAM MEETING RECORD}

This form is an outline for the interdisciplinary team to follow during their meetings together. It helps to identify and focus the meeting function, and provides a record of the meeting for the chart.

Use: Quarterly and interim meetings of the interdisciplinary team.

Chart Location: This form would be in the care plan section of the chart. If the care plans are stored in a separate binder, this form would be located with the current care plans. 


\section{INTERDISCIPLINARY TEAM MEETING RECORD}

Resident Name:

Date:

Admission MDS: $\square$ Quarterly Review:

$\square$ Annual MDS: $\square$

Significant Change: $\square$ Significant Correction: $\square$ Other:

Brief Summary of Meeting:

Physical Restraint

Yes $\square$ No $\square$ N/A $\square$ Current Consent $\square$

Reviewed/Discussed:

Chemical Restraint

Yes $\square$ No $\square$ N/A $\square$ Current Consent $\square$

Reviewed/Discussed:

Self-Medication Reviewed/ Yes $\square$ No $\square$ N/A $\square$ CurrentConsent $\square$

Discussed:

Advance Directives Status $\quad$ Yes $\square$ No $\square \quad$ Current Consent $\square$

Discussed

DNR Status (including $\quad$ Yes $\square$ No $\square \quad$ Current Consent $\square$ community) Discussed:

Face Sheet Checked for $\quad$ Yes $\square$ No $\square$

Accuracy

Current LTC Screening $\quad$ Yes $\square$ No $\square$ N/A $\square$

Form in Chart

Current Guardianships, $\quad$ Yes $\square$ No $\square$ N/A $\square$

Including Roger's, in

Chart

Current Health Care Proxy Yes $\square$ No $\square$

in Chan

Medical Record Purged per Yes $\square$ No $\square$

Policy, for Outdated,

Nonvalid Consents: 
444 Appendix: Standardized Forms

Attendance:

Name

Title

Discipline

Estimated Length of Stay:

Submitted by:

Title: 


\section{PREADMISSION SCREENING SCENARIO}

OBRA Preadmission screening is required when

Any new admission to a nursing facility occurs.

Any in-patient psychiatric hospitalization occurs.

A nursing home resident is discharged to the community and decompensates, necessitating readmission to a nursing facility. At that time, a new level I screening by the home care/hospital will trigger the PASRR process.

OBRA Preadmission screening is not required when

A nursing home resident transfers from one nursing facility to another. The sending facility should include a copy of the most recent OBRA screening with the accompanying paperwork.

A nursing home resident is sent to a hospital for medical reasons. The 20-day bed-hold practice often utilized by discharge planners does not enter into consideration. This scenario also includes residents who are discharged to a different nursing facility after a medical admission. It is incumbent on the receiving facility to contact the previous nursing home or the OBRA offices for a copy of the most recent OBRA screening.

A nursing home resident is approved for a 90-day stay and has received an OBRA/PASRR during that time period. No additional screening will be required if a conversion to long-term nursing home level of care is requested. Those residents admitted to an in-patient psychiatric hospital at or before the 90-day mark will fall under scenario II.

In order to ensure compliance with this federally mandated process, all hospital, nursing facility, and home-care staff persons are encouraged to review each admission/discharge carefully. 


\section{IDENTIFICATION SCREENING FOR NONRECIPIENTS WAIVING LTC SCREENING (MASSACHUSETTS EXAMPLE)}

This form is to be completed only for those individuals who meet the eligibility criteria for nursing facility services as described in 106 CMR 456.251 through 456.266 .

\begin{tabular}{|l|l|l|l|}
\hline \multicolumn{2}{|l|l|}{ Provider Information Section } & \multicolumn{2}{|l|}{ Recipient Information Section } \\
\hline Provider Name \& Address & Recipient's Name \& Address & Sex \\
\hline & & $\begin{array}{l}\square \mathrm{M} \\
\square \mathrm{F}\end{array}$ \\
\hline Provider's Telephone No. & Provider No. & Date of Birth & Recipient ID No. \\
\hline( & & & \multicolumn{2}{l}{} \\
\hline
\end{tabular}

\section{SECTION I. IDENTIFICATION}

Does the individual have a documented diagnosis or treatment history of any of the following major mental disorders?

$\square$ Schizophrenia

$\square$ Major Affective Disorder

$\square$ Atypical Psychosis

$\square$ Paranoia

$\square$ Schizoaffective Disorder

$\square$ None of the above

Does the individual have a documented diagnosis or treatment history of mental retardation, developmental disability, or a related condition?

$\square$ Yes $\square$ No

Does the individual exhibit any evidence of a major mental illness?

$\square$ Yes $\square$ No

Has the individual ever received inpatient or outpatient psychiatric treatment?

\section{$\square$ Yes $\square$ No}

Has the individual received services for mental retardation, developmental disability, or a related condition from an agency that serves the mentally retarded, the developmentally disabled, or both?

$\square$ Yes $\square$ No 
Does the individual exhibit any evidence that may indicate mental retardation, developmental disability, or a related disorder?

Yes $\square$ No

(If you have answered "No" to all of the above, skip Section II and go on to Section III.)

\section{SECTION II. EXEMPTIONS FOR MENTAL ILLNESS ONLY}

(Complete only if you answered "Yes" to at least one question in Section I.) Does the individual meet any of the following conditions? (Check those that apply.)

Alzheimer's disease or other dementia (requires supportive documentation)

$\neg$ Comatose

$\square$ Ventilator-dependent

$\square$ Brain-stem level functioning

$\square$ Severe chronic obstructive pulmonary disease

$\square$ Severe Parkinson's disease

$\square$ Severe Huntington's disease

Severe amyotrophic lateral sclerosis

Severe congestive heart failure

$\square$ Convalescent care not to exceed 30 days following acute hospital stay

$\square$ Terminal illness certified by physician (less than six-month prognosis)

\section{SECTION III. CERTIFICATION}

Based on the above findings, I certify that (check one):

There is no indication of mental illness, mental retardation, or developmental disability.

Mental illness is indicated, but individual meets one of the exemptions in Section II.

Mental illness, mental retardation, or developmental disability is indicated and referral has been made to the appropriate agency for assessment.

Signature:

Date:

Title:

Time: 
Nursing facilities have all developed their own notices to inform residents of proposed transfers or discharges. Written notices must be given to the resident and their designee 30 days before the proposed transfer or discharge, or in limited circumstances, as soon as practicable before the action.

All notices are written in 12-point type or larger. Notification includes the name of the facility, the transfer or discharge decision, the place where the resident is going, the reason(s) for the transfer, and both the date of the notice and the date of the proposed transfer. Included in all notifications are the resident's rights and a form describing their right to appeal the facility decision and agencies, addresses, and telephone numbers to help. Notices also include the arrangements for services a resident will be receiving post transfer or discharge.

Transfer and discharge include any movement from the certified section of the nursing facility to the noncertified section of the facility and movement from the noncertified section of the facility to the certified section. Transfer and discharge include transfer to the hospital as well as community discharge.

If a resident appeals a decision, the facility cannot move the resident until the appeal is resolved through a fair hearing process. Residents have 30 days to make an appeal after receiving a transfer/discharge notice, or 14 days after an emergency discharge. The hearing decision is provided within a 45-day window. When a resident requests an expedited appeal, the hearing is scheduled as soon as possible (within a 7-day time frame), and a decision is made as soon as possible (within a 7-day time frame). Residents, in the expedited appeal, are notified verbally, approximately 48 hours before the hearing.

Use of Forms: All transfers/discharges in the nursing facility. These forms are not used for room changes on the same certified section of the facility.

Chart Location: These forms may be kept in a number of places. In the chart, the Misc. section or the Social Service section generally contain copies of these notices. Some facilities have separate binders to include copies of these notices. Other facilities keep the copies in the Social Service office resident file. 


\section{EXAMPLE OF 30-DAY NOTICE OF INTENT TO TRANSFER/ DISCHARGE RESIDENT}

\section{(Date of notice)}

Notice to:

Copies to:

(Name of resident)

(Name of representative)

The purpose of this letter is to inform you that (Name of nursing facility) seeks to (transfer/discharge) you to (Name of receiving facility, unit, or noninstitutional setting) on (date). The reason(s) the nursing facility seeks to (transfer/discharge) you is/are:

(Reason must be stated in specific detail)

The nursing facility has made arrangements for you to receive:

Services to be Provided: $\quad$ Name of Provider/Location of Discharge:

YOU HAVE THE RIGHT TO APPEAL THE NURSING FACILITY'S PLAN TO TRANSFER OR DISCHARGE YOU. IF YOU DISAGREE WITH THIS DECISION, YOU MUST REQUEST A HEARING WITH THE DEPARTMENT OF PUBLIC WELFARE WITHIN 30 DAYS OF RECEIVING THIS NOTICE. IF YOU REQUEST A HEARING, YOU CANNOT BE TRANSFERRED OR DISCHARGED UNTIL 30 DAYS AFTER THE APPEAL DECISION IS RENDERED.

The person at the nursing facility who is responsible for supervising your transfer or discharge is You should notify this person if you request an appeal or if you have any questions regarding this notice. You can send a request for a hearing by mail or fax. A hearing request form is enclosed with this notice. The nursing facility staff must help you in completing the request for a hearing if you request assistance.

You have the right to be represented at a hearing by an attorney or other advocate. For additional information or assistance, contact the following offices: Local Long-Term Care Ombudsman Program 
(Address and telephone number)

Disability Law Center or Center for Public Representation (as appropriate)

(Address and telephone number)

For free legal advice or representation, contact:

Local Legal Services Office

(Address and telephone number)

(Notice 1-Page 1) 


\section{EXAMPLE OF NOTICE OF NURSING FACILITY RESIDENT'S RIGHTS REGARDING A TRANSFER/DISCHARGE}

You may only be transferred or discharged for one of the following reasons: The move is necessary for your own welfare and your needs cannot be met within the nursing facility;

Your health has improved sufficiently that you no longer need the services provided by the nursing facility;

The safety of individuals in the facility is endangered;

The health of individuals in the facility would otherwise be endangered;

You have failed, after reasonable and appropriate notice, to pay for (or failed to have Medicaid pay for) a stay in the facility; or

The facility is to be closed.

In general, you cannot be transferred or discharged until 30 days after you receive the nursing facility's notice, unless you agree to an earlier date. If you have resided in the nursing facility for less than 30 days, or your health has improved and you no longer need nursing care, or the health and safety of you or others in the facility is endangered, or you have urgent medical needs, the nursing facility can give you less than 30 days notice of its intent to transfer you and you will have the right to have an expedited appeal.

You have the right to appeal a nursing facility's plan to transfer or discharge you. You can file a request for a hearing with the department of Public Welfare's Division of Hearings. If you request an appeal prior to being moved, you cannot be transferred or discharged until after the hearing officer issues a decision in favor of the nursing facility. If the grounds for the planned transfer or discharge is nonpayment, you have the right to pay any amount owed. If you do this, the nursing facility may not transfer or discharge you for nonpayment.

If the hearing officer agrees with you, the nursing facility will not be permitted to transfer or discharge you. If the hearing officer decides in favor of the nursing facility, you will generally be allowed 30 days from the date you receive the decision to prepare for the move. If the reason for the transfer or discharge is one in which the nursing facility is allowed to give you less than 30 days notice, you will be allowed 5 days from the date you receive the decision to prepare for the move.

(Form 2-Page 1) 


\section{EXAMPLE OF A REQUEST FOR A HEARING}

To be completed by the resident or the resident's representative:

(Name and address of resident)

(Name and address of resident's

representative)

(Social Security Number of Resident)

I WISH TO APPEAL THE PLAN OF (Name of nursing facility) TO TRANSFER OR DISCHARGE ME.

Attached is a copy of the transfer/discharge notice provided to me by the facility and received on (Date).

Date:

Signature of Resident or Representative

Mail or fax this form to

\section{DEPARTMENT OF PUBLIC WELFARE}

DIVISION OF HEARINGS

Give a copy of this form to the nursing facility contact person.

You will be notified by mail of the date, time, and hearing officer who will hear your appeal. Failure to appear at the hearing without good cause may result in dismissal of the appeal.

(Form 1-Page 1) 


\section{EXAMPLE OF NOTICE OF INTENTTOTRANSFER OR DISCHARGE RESIDENT WITH EXPEDITED APPEAL}

(Date of notice)

Notice to:

(Name of resident)

Copies to:

(Name of representative)

The purpose of this letter is to inform you that (Name of nursing facility) seeks to (transfer/discharge) you to (Name of receiving facility, unit, or noninstitutional setting) on (Date). The reason(s) the nursing facility seeks to (transfer/ discharge) you is/are:

(Reason mustbestated in specific detail)

The nursing facility has made arrangements for you to receive:

Services to be Provided: Name of Provider/Location of Discharge:

YOU HAVE THE RIGHT TO APPEAL THE NURSING FACILITY'S PLAN TO TRANSFER OR DISCHARGE YOU. IF YOU DISAGREE WITH THIS DECISION, YOU MUST REQUEST A HEARING WITH THE DEPARTMENT OF PUBLIC WELFARE WITHIN 14 DAYS OF RECEIVING THIS NOTICE. IF YOU REQUEST A HEARING, BEFORE BEING MOVED, YOU CANNOT BE MOVED UNTIL 5 DAYS AFTER YOU RECEIVE THE DECISION OF THE HEARING OFFICER.

If you have resided in the nursing facility for less than 30 days, or your health has improved and you no longer need nursing care, or the health and safety of you or others in the facility is endangered, or you have urgent medical needs, the nursing facility can give you less than a 30-day notice. In all other situations, the nursing facility must give you 30 days advance notice of its intent to transfer or discharge you.

The person at the nursing facility who is responsible for supervising your transfer or discharge is . You should notify this person if you request an appeal or if you have any questions regarding this notice. You can send a request for a hearing by mail or fax. A hearing request form is enclosed with this notice. The nursing facility staff must help you in completing the request for a hearing if you request assistance. 
You have the right to be represented at a hearing by an attorney or other advocate. For additional information or assistance, contact the following offices:

Local Long Term Care Ombudsman Program

(Address and telephone number)

Disability Law Center or Center for Public Representation (as appropriate)

(Address and telephone number)

For free legal advice or representation contact:

Local Legal Services Office

(Address and telephone number)

(Notice 2-Page 1) 


\section{BED-HOLD FORM}

The bed-hold form is used to inform residents and their designated family members of their rights to hold a bed when there is a medical leave of absence.

Copies to:

Resident

Family or responsible party

The chart

Use: Bed-hold forms are required to be given at the time of transfer and discharge. Notification of this process should be noted in the social service notes in the chart.

Chart Location: The copies of these notices are often held in the Social Service section, or in the Misc. section. Some facilities have copies in resident files in the social service office. 


\section{BED-HOLD POLICY AND NOTICE (MASSACHUSETTS SAMPLE)}

Date:

Resident name:

Transferred to:

Responsible party:

Address:

1. Medicaid: Residents covered by the Medicaid Program are entitled to a bed hold when they are transferred to a hospital or for a therapeutic leave of absence. Under the Medicaid Program, the duration of this bedhold for a medical leave of absence is up to During this period, the resident is permitted to return and resume residence in the facility. For Medicaid recipients, private payment may be provided after for each day the bed is reserved. In the event that a bed is not reserved beyond a medical leave of absence, the resident is discharged. If the resident's hospitalization exceeds the bed-hold period, the resident will be readmitted to (the nursing facility) of (town) immediately upon the first availability of an appropriate bed. This readmission is provided that the resident's needs may continue to be met by (nursing facility) and the resident is eligible for Medicaid services.

According to Massachusetts state Medicaid regulations, the duration of the bed hold is . Your bed-hold period is from:

(A) Date of Transfer:

(B) Date of discharge:

2. Medicare or Private Insurance: Medicare and Private Insurances do not pay for a bed hold. Therefore, your bed-hold will be based on your alternative funding source. Please see Medicaid Policy (\#1) or Private Policy (\#3).

3. Private Pay: For residents paying privately, payment must continue for all the days the bed is reserved. Unless otherwise notified, the facility will presume the bed is to be reserved, and the resident will pay for the full private rate during a medical leave of absence. The resident and/or responsible party may opt to cease a bed hold reservation at any time, in which case the resident will be discharged and the room vacated of personal belongs (which will be stored according to nursing facility policies). 
According to the Private Plan, your bed hold period begins on: Date of Transfer:

I agree to pay the private or the semi-private room rate of $\$$

per day for name of resident, while he/she is hospitalized. I was notified by telephone on

Signature:

Date:

Relationship to resident: 


\section{COMMUNITY DISCHARGE PLAN FORM}

This is a form devised to assist social workers in their discharge of residents to the community.

The uses of this form are:

A discharge planning worksheet;

A comprehensive planning tool with residents and families;

A planning tool with other staff members.

Chart location: Generally this form would be in the social service office file or in the Social Service section of the resident chart. 


\section{COMMUNITY DISCHARGE PLAN}

Name:

Address:

Phone:

$\square$ Notice of discharge (expedited) given with resident rights and 30-day readmittance

Date:

The following areas may be included in the resident discharge plan:

1. Facility physician's order for discharge:

$\square$ Name of attending physician in the community:

Phone \#

3 Page Referral(s)

$\square$ Fax 3-page referral $\square$ Resident hand carry home referral

$\square$ Mailed referral

2. Medications:

$\square$ Medications given at time of discharge \# of days:

(See nursing page 1)

3. Financial arrangements for all community services:

$\square$ Medicare to pay for continuing care needs

$\square$ Medicaid

$\square$ Private insurance $\quad \square$ Private pay

4. Transportation to home:

$\square$ Family/friend car

$\square$ Wheelchair van

5. Home-care services:

$\square$ Visiting Nurses

Date service to begin:

$\square$ Physical Therapy

$\square$ Occupational Therapy

$\square$ Home Health Aide $\square$ Ambulance $\square$ Other:

Taxi $\square$ Elder Services

Date service to begin:

$\square$ Meals on Wheels

$\square$ Homemaker

$\square$ Other: 
$\square$ Social Worker:

$\square$ Hospice $\square$ Assisted Living Setting

6. Special equipment at time of discharge:

$\square$ Walker

$\square$ Bathtub bench Where

delivered:

$\square$ Cane

$\square$ Grab bars

Date to be

delivered:

$\square$ Wheelchair

$\square$ Oxygen

$\square$ Commode

$\square$ Other:

7. Emergency Home Medical system:

$\square$ Type: $\square$ Date service to start:

8. Family available to assist with:

$\square$ Meet at facility and assist with discharge
$\square$ Meal preparation
$\square$ Medication monitoring
$\square$ Transportation
$\square$ Finances
$\square$ Other:

Key family members:

EMB 2012 


\section{NURSING HOME SOCIAL WORK PRACTICE STANDARDS: AN EXAMPLE FROM MASSACHUSETTS}

\section{INTRODUCTION}

In 1991, the NASW Nursing Home Committee of Massachusetts made a decision by which they hoped to impact the practice of social work in nursing homes throughout the Commonwealth of Massachusetts. The Committee decided to develop its own Practice Standards rather than rely on the State or the nursing home industry. This development was preceded by over 12 years of work by the Committee with the Department of Public Health in an attempt to formulate new State regulations regarding social work practice in nursing homes.

The work was abandoned by the State following the election of a new governor. This disappointment led the committee to empower the social work community to take charge of their own professional destiny and to develop their own standards. The Committee began its work by forming a Practice Standards Sub-Committee, composed of social workers from different geographical areas. One of the primary goals was to involve as a many social workers as possible, so they could claim ownership in the project. This was accomplished through the participation of hundreds of social workers for a 4-year period. Regional social workers from the Berkshires to Cape Cod drafted different sections of the document, which were reviewed by the Sub-Committee.

There was an ongoing exchange of material between the groups. This work was supplemented by the involvement of participants at the Annual Nursing Home Social Work Conference, which is attended by over 300 people. Attendees provided the Sub-Committee with comments, which were reviewed and evaluated. The project culminated with a series of seven statewide hearings, which were attended by over 140 social workers. The material from the hearings was evaluated and incorporated into a final draft. This was adopted by the Executive Committee and the Board of Directors of The Massachusetts Chapter of NASW.

These Standards provide the reader with a foundation for social work practice in the nursing home. They are not intended to be a manual about how to practice social work in the nursing home. How social workers practice is dependent upon individual experiences, education, and levels of competency. These standards begin with a preamble, which is an overview of the document. It is followed by five basic social work functions. They are 
administration, advocacy, clinical, consultation, and education. It concludes with personnel practices. Each section has an introduction that provides the rationale for the standard and is followed by an interpretation.

In conclusion, these Practice Standards are a constant in the midst of an ever-changing health care system. The industry has seen the birth of Medicare, Medicaid, and Managed Health Care. The challenges faced by social workers, health care professionals, and consumers is to maintain these standards which strive to assure humane and compassionate treatment of nursing home residents and their families.

- The Practice Standards Committee

Ed Alessi

Frank Baskin, Project Coordinator

Diane Finnemore

Carolyn Sones 


\section{PRACTICE STANDARDS}

\section{PREAMBLE}

The nursing home social worker is mandated to adhere to the professional code of Ethics of the National Association of Social Workers. We have a legal obligation to adhere to governmental laws. We have a professional responsibility to provide good service, and to bring about change when laws unjustly affect our client population. We are responsible for fostering a climate, policies, and routines, which enable residents to retain individuality, independence, and dignity.

\section{ADMINISTRATION}

\section{INTRODUCTION}

The Social Worker shall carry out administrative functions in order to meet the needs of residents.

\section{STANDARD A}

The social worker shall participate in the development and implementation of policies regarding resident care, social work practice, and personnel policies.

\section{Interpretation}

The Social Worker shall be a part of the interdisciplinary team that meets regularly to review facilities' policies and procedures regarding compliance with State and Federal Regulations.

The Social Worker shall influence policies that affect resident care and the quality of residents' lives.

The Social Worker shall be involved with the development of policies that affect social service job descriptions, employment criteria, work standards, job benefits.

\section{STANDARD B}

The Social Worker shall be knowledgeable of and maintain regular contact with all community resources.

Interpretation

The Social Worker shall develop a knowledge base of community resources which are available to the long-term care residents as well as those residents with discharge potential. 
The Social Worker shall assume a proactive role in the supporting and utilizing of community resources.

The Social Worker shall maintain a current resource file.

The Social Worker shall educate the community regarding the nursing home as a resource.

\section{STANDARD C}

The Social Worker shall participate in quality assurance in order to assure effective practice of social work in meeting residents' needs.

\section{Interpretation}

The Social Worker shall participate in regular quality assurance interdisciplinary team meetings.

The Social Worker shall identify problems and develop and implement studies relative to issues affecting residents.

The Social Worker shall develop recommendations resulting from quality assurance data.

\section{STANDARD D}

The Social Worker shall understand and meet all government requirements for social service documentation.

\section{ADVOCACY}

\section{INTRODUCTION}

The Social Worker shall be an advocate who promotes self-advocacy for residents and an increased awareness of issues that impact on the quality of life of nursing home residents.

\section{STANDARD A}

The Social Worker shall be knowledgeable of nursing home, community, and governmental practices that directly or indirectly affect nursing home residents.

Interpretation

The Social Worker shall work with the interdisciplinary team and administration to promote and protect residents' rights and the psychosocial well-being of each resident. 
The Social worker has legal and professional responsibility to prevent and address resident abuse.

The Social Worker shall identify community changes and opportunities such as legislation, regulations, and programs that affect nursing homes residents.

\section{STANDARD B}

The Social Worker shall assist residents, family/significant others, and staff on how to effectively advocate for the residents.

\section{Interpretation}

The Social Worker shall work with residents, family/significant others, and staff individually or in groups to provide support, information, and organization for taking a more proactive role in making changes which improve the quality of life for individual residents as well as within the nursing home and in the community.

\section{CLINICAL}

\section{INTRODUCTION}

The Social Worker shall be responsible for doing psychosocial assessment, social history, care planning, and clinical interventions with residents and family/significant others in order to alleviate social and emotional problems.

\section{STANDARD A}

The Social Worker shall develop individualized, comprehensive psychosocial assessments for each resident.

\section{Interpretation}

The Social Worker shall record and develop psychosocial history and assessments in a timely fashion to be a part of the resident's permanent record.

The Social Worker shall include the resident, family members, significant others, and referral sources as sources of data.

The Social Worker shall consider the following: identifying data, cultural and background information, personal characteristics, interpersonal relationships, functioning levels, orientation, attitudes, decision-making abilities, mental status, coping, behavior patterns, and legal issues.

The Social Worker shall develop discharge planning to reflect the resident's potential to return to the community. 
The Social Worker shall assess the needs and nature of counseling for residents including the use of community mental health services.

\section{STANDARD B}

The Social Worker shall participate in the development of an interdisciplinary treatment plan for each resident.

\section{Interpretation}

The plan shall include: identified psychosocial problems of resident, family and significant others insofar as they impact on the resident; short and long-term goals which attempt to resolve identified problems; approaches for social work intervention.

Discharge planning and referrals to community resources (as appropriate).

Residents and their family/significant others shall be encouraged to participate in the formulation process, ongoing evaluation, and reassessment with the interdisciplinary team.

\section{STANDARD C}

The Social Worker shall ensure the appropriate provision of counseling services for residents with identified psychosocial needs.

\section{Interpretation}

Individual, group, and family treatment modalities shall be utilized.

During the initial period following admission the Social Worker shall provide intensive and frequent contacts with the resident and family/significant others.

The Social Worker shall provide time-limited counseling services to residents as deemed appropriate.

The Social Worker shall refer to appropriate community mental health services.

\section{CONSULTATION}

\section{INTRODUCTION}

Social service consultation shall be provided on a planned basis with sufficient frequency to enable the Social Worker, administration, and facility staff to meet the psychosocial needs of residents. 


\section{STANDARD A}

The consultant shall provide clinical consultation to the staff Social Worker.

\section{Interpretation}

The Social Worker shall review clinical services focusing on psychodynamics, delivery, and documentation of services.

The consultant shall assist the staff Social Worker to further develop and maximize skills in interviewing, assessment, recording, and treatment modalities.

\section{STANDARD B}

The consultant shall provide general consultation to the staff Social Worker.

\section{Interpretation}

The consultant shall discuss administrative and organizational issues; program planning, professional development and long-term care issues.

The consultant shall provide support to the Social Worker and enable the Social Worker to self-advocate.

\section{STANDARD C}

The consultant shall provide consultation to the administration.

\section{Interpretation}

The consultant shall discuss program planning, policy development, and priority setting regarding social services.

The consultant shall review the function and role of the staff Social Worker (including personnel issues).

The consultant shall advocate for social services with administration and other staff members.

\section{STANDARD D}

The consultant shall provide consultation to the facility staff.

\section{Interpretation}

The consultant shall be available to provide case consultation regarding psychosocial needs of resident and family/significant others. 
The consultant shall provide in-service education to the staff on selected topics or clinical concerns.

\section{EDUCATION}

\section{INTRODUCTION}

The Social Worker shall educate resident, family/significant others, and staff in order to create an atmosphere where residents are cared for, respected, and appreciated as individuals.

\section{STANDARD A}

The Social Worker shall educate nursing home staff on an ongoing basis regarding the Social Worker's role in the facility and the psychosocial needs of residents and their family/significant others.

Interpretation

The Social Worker shall have regular contact with nursing home staff and participate in periodic planned in-services. This allows the Social Worker to help sensitize the staff to

The psychosocial problems of aging, illness, and disability, both in general and how they specifically impact a particular resident or family member.

The importance of each staff member's involvement in caring for residents.

An awareness of cultural diversity.

The role of the Social Worker.

\section{STANDARD B}

The Social Worker shall educate residents and family/significant others about living in a nursing home setting and the options available to them.

\section{Interpretation}

The Social Worker shall have regular contact with residents and their family/ significant others to help them understand

Their rights and responsibilities.

How to problem-solve when conflicts arise.

What community, social, and health services are available to them, including discharge planning. 


\section{STANDARD C}

The Social Worker shall supervise students assigned to social services.

Interpretation

The Social Worker shall assign tasks in accordance with guidelines from the student's school.

The Social Worker shall be accountable for the student's work and documentation.

\section{PERSONNEL PRACTICES}

\section{INTRODUCTION}

The Social Worker shall be in compliance with government regulations and shall adhere to the professional code of ethics of NASW and the Social Work Licensing Boards. The Social Worker shall be provided with the necessary administrative support in order to carry out the Social Work mission.

\section{STANDARD A}

Any Social Worker who staffs a long-term care facility shall have a license in the Commonwealth of Massachusetts at the Licensed Social Worker (LSW) or higher level of licensure.

Interpretation

The Social Worker shall be licensed in accordance with state and federal regulations.

The minimum number of Social Worker hours per week shall be determined on a ratio of 1 social work hour per 1.5 residents.

Frequent transfers, admissions, and discharges shall warrant an increase in social work hours per resident.

\section{STANDARD B}

The Social Worker shall receive supervision by a licensed MSW Social Worker (LICSW or LICSW eligible).

\section{Interpretation}

The number of hours per month of supervision shall be based on a minimum ration of 1 hour of supervision to every 5 hours of social work per week. 


\section{STANDARD C}

The Social Worker shall meet the requirement for continuing education as designated by the Commonwealth.

\section{Interpretation}

The Social Worker shall be provided with the opportunity to complete continuing education requirements in order to maintain his/her social work license.

The Social Worker shall be reimbursed by the employer and be provided the time to attend educational programs that shall benefit the facility and enhance his/her practice.

\section{STANDARD D}

The Social Worker shall engage in activities which shall increase professional knowledge and enhance professional development.

\section{Interpretation}

The Social worker shall expand knowledge and skills levels to increase the level of proficiency in carrying out the identified social work roles.

The Social Worker shall have access to adequate and updated written material pertinent to the performance and enhancement of the social work function.

The Social Worker shall be provided with the time and opportunity to participate in professional organizations and to network with colleagues.

\section{STANDARD E}

The Social Worker shall require adequate supplies, clerical services, and office space to effectively and adequately carry out the social work functions.

\section{Interpretation}

The Social Worker shall have a quiet, comfortable, secure, private, furnished, and handicapped accessible office. This shall ensure confidentiality for residents, family, and staff.

The Social Worker shall have a secure file cabinet in the office to maintain confidentiality of records.

The Social Worker shall have a telephone and have access to other modes of communication (fax machine, computers, etc.) in order to effectively carry out his/her responsibilities. 
The Social Worker shall be provided with adequate clerical services.

\section{STANDARD F}

The nursing home shall have written policies in place which describe the contact between the Social Worker and the nursing home in order to identify mutual expectations during the Social Worker's employment.

Interpretation

A written contract shall identify the terms of employment between the Social Worker and the nursing home.

The Social Worker's immediate supervisor shall provide an annual written and oral evaluation of the Social Worker. 


\section{HEALTH CARE PROXY FORM (MASSACHUSETTS AND NEW YORK)}

The Health Care Proxy form allows a resident (principal) to select a person to have the authority to make health care decisions for them. The Health Care Proxy is not effective until the resident (principal) is determined, by their attending physician, in writing, to no longer have the capacity to make those decisions.

Uses: This form is used when the resident is determined to be no longer capable of making health care decisions for themself including such issues as life-sustaining treatment or psychoactive medication. The Health Care Proxy is the recognized instrument for making Advance Directives.

Chart Location: The Health Care Proxy is generally found in the Legal section of the chart. Some charts have plastic sleeves that protect this type of document. Occasionally, this type of document will be kept with the admission paperwork. 


\section{MASSACHUSETTS HEALTH CARE PROXY}

1. I,

(Principal-PRINT your name)

residing at

(Street)

(City or Town)

(State)

appoint as my Health Care Agent:

(Name of person you choose as Agent)

of

(Street)

(City or Town)

(State)

(Phone number)

(Optional; If my agent is unwilling or unable to serve, then I appoint as my Alternate: , of .)

(Street) (City or Town) (State) (Phone number)

2. My Agent shall have the authority to make all health care decisions for me, including decisions about life-sustaining treatment, subject to any limitations I state below, if I am unable to make health care decisions myself. My Agent's authority becomes effective if my attending physician determines in writing that I lack the capacity to make or to communicate health care decisions. My Agent is then to have the same authority to make health care decisions as I would if I had the capacity to make them except (here list the limitations if any, you wish to place on your Agent's authority):

I direct my Agent to make health care decisions based on my Agent's assessment of my personal wishes. If my personal wishes are unknown, my Agent is to make health care decisions based on my Agent's assessment of my best interests. Photocopies of this Health Care Proxy shall have the same force and effect as the original.

3. Signed:

Complete only if Principal is physically unable to sign: I have signed the Principal's name above at his/her direction in the presence of the Principal and two witnesses. 
Name

\section{City or Town State}

4. WITNESS STATEMENT: We, the undersigned, each witnessed the signing of this Health Care Proxy by the Principal or at the direction of the Principal and state that the Principal appears to be at least 18 years of age, of sound mind and under no constraints or undue influence. Neither of us is named as the Health Care Agent or Alternative in this document.

In our presence this day of

Witness \#1 Witness \#2

Signature

Name:

Print
Signature

Name:

\section{Print}

Address: Address:

5. Statements of Health Care Agent and Alternate (Optional):

Health Agent: I have been named by the Principal as the Principal's Health Care Agent by this Health Care Proxy. I have read this document carefully, and have personally discussed with the Principal his/ her health care wishes at a time of possible incapacity. I know the Principal and accept this appointment freely. I am not an operator, administrator, or employee of a hospital, clinic, nursing home, rest home, Soldiers Home, or other health care facility where the Principal is presently a patient or resident or has applied for admission. Or if I am a person so described, I am also related to the Principal by blood, marriage or adoption. If I called upon and to the best of my ability, I will try to carry out the Principal's wishes.

Signature of Health Care Agent:

Alternate: I have been named by the Principal as the Principal's Alternate by this Health Care Proxy. I have read this document carefully, and have personally discussed with the Principal his/her health care wishes at a time of possible incapacity. I know the Principal and accept this appointment freely. I am not an operator, administrator, or employee of a hospital, clinic, nursing home, rest home, Soldiers 
Home, or other health care facility where the Principal is presently a patient or resident or has applied for admission. Or if I am a person so described, I am also related to the Principal by blood, marriage, or adoption. If I am called upon and to the best of my ability, I will try to carry out the Principal's wishes.

Signature of Alternate: 
1.

I, , hereby appoint

(name)

(address)

(telephone number)

as my health care agent to make any and all health care decisions for me, except to the extent that I state otherwise. This proxy shall take effect when and if I become unable to make my own health care decisions.

Optional instructions: I direct my agent to make health care decisions in accord with my wishes and limitations as stated below, or as he or she otherwise knows. (Attach additional pages if necessary.)

(Unless your agent knows your wishes about artificial nutrition and hydration [feeding tubes], your agent will not be allowed to make decisions about artificial nutrition and hydration. See instructions on reverse for samples of language you could use.)

Name of substitute or fill-in agent if the person I appoint above is unable, unwilling, or unavailable to act as my health care agent:

(name)

(address)

(telephone number)

Unless I revoke it, this proxy shall remain in effect indefinitely, or until the date or conditions stated below. This proxy shall expire (specific date or conditions, if desired):

Signature

Address

Date 
5. Statement by Witnesses (must be 18 or older)

I declare that the person who signed this document is personally known to me and appears to be of sound mind and acting of his or her own free will. He or she signed (or asked another to sign for him or her) this document in my presence.

Witness 1

Witness 2

Witness 3

Address 


\section{HEALTH INSURANCE PORTABILITY AND ACCOUNTABILITY ACT POLICY EXAMPLE}

\begin{tabular}{|l|l|}
\hline Policy \& Procedure & Function: \\
HIPAA/Privacy & Number: \\
Designated Record Set & Prior Issue: \\
Company & Effective Date: \\
Logo & \\
\hline
\end{tabular}

\section{PURPOSE}

To describe the documents that comprise the Designated Record Set.

\section{POLICY}

The HIPAA Privacy Rule requires that residents be permitted to request access and amendment to their Protected Health Information ("PHI") that is maintained in a Designated Record Set. This policy documents the contents of the Designated Record Set.

\section{PROCEDURE}

1. The Designated Record Set is a group of records maintained by or for the Facility that consists of the Medical Records and billing records about a resident and is used, in whole or in part, by or for the Facility to make decisions about the resident. The term record means any item, collection, or grouping of information that includes $\mathrm{PHI}$ and is maintained, collected, used, or disseminated by or for the Facility.

2. The Facility maintains the following as the Designated Record Set:
a. The resident's Medical Record,
b. The resident's Business Office File, and
c. The resident's Personal Health Records.

3. The Resident Medical Record includes, at a minimum, the following:
- Activity documentation
- Admission/readmission documentation
- Advance directives
- Assessments, flow sheets
- Care plan 
- Informed consent

- History and physical exams and other related hospital records

- Minimum Data Set

- Medication and treatment records

- Nursing documentation/progress notes

- Nutritional services documentation

- Physician and professional consultant progress notes

- Physician's orders

- Rehabilitative and restorative therapy records

- Reports from lab, $\mathrm{x}$-ray and other diagnostic tests

- Face sheet

- Social service documentation

a. Excluded from the Medical Record are source data, including photographs, films, monitoring strips, videotapes, slides, worksheets and daily communication sheets, and shadow files or charts, unless such data is used to make decisions related to the resident's care.

b. If records from other providers are used by the Facility to make decisions related to the care and treatment of the resident, then these records are considered part of the Designated Record Set as well as the Medical Record, e.g., history and physical, discharge summary and labs from previous acute care hospitalization.

4. The Resident's Business Office File includes, at a minimum, the following:

- Admission documents

- Acknowledgement of receipt of the Facility's Notice of Privacy Practices

- Correspondence relating to coverage and payment from insurance companies, health plans, Medicare, Medicaid and other payer sources

- Resident claim information, including claim, remittance, eligibility response, and claim status response

- Statements of account balance

- Collection activity documents and correspondence 
5. Personal Health Records consist of the resident's personal health information provided to the Facility by the resident. If such records are used by the Facility to make health care related decisions, provide care services, or document observations, actions or instructions, then the records will be considered part of the Designated Record Set.

6. The following are excluded from the Designated Record Set: Administrative data, such as audit trails, appointment schedules, and practice guidelines that do not imbed PHI. Also excluded are incident reports, quality assurance data, vital certificate worksheets, and derived data such as accreditation reports, anonymous resident data for research purposes, public health records, and statistical reports.

7. The Designated Record Set is to be retained according to state and federal regulations and following Facility or company retention procedures. 


\section{ROOM CHANGE DOCUMENTATION}

\section{SOCIAL SERVICE PROGRESS NOTES}

Date and time of projected move:

From room

to room

Reason for room change:

- Resident/Family is requesting room change.

- Level of care requires a change.

- Need for infection control precautions/isolation requirements.

- Behavioral issues (safety concerns).

- Other (explain)

Resident and Responsible Notified: Yes No __ Date

Name of Responsible Party Notified:

Additional Comments:

Completed by:

Signature of staff member completing room change documentation

Date

Resident Name

Physician

Med. Rec. \# 